\title{
Emotional Intelligence and Academic Engagement in Adolescents: The Mediating Role of Self-Esteem
}

This article was published in the following Dove Press journal:

Psychology Research and Behavior Management

\author{
Ana Belén Barragán Martín' \\ María del Carmen \\ Pérez-Fuentes (D) \\ María del Mar Molero Jurado' \\ África Martos Martínez' \\ María del Mar Simón Márquez' \\ Maria Sisto' \\ José Jesús Gázquez Linares ${ }^{2}$ \\ 'Department of Psychology, Faculty of \\ Psychology, University of Almería, \\ Almería, 04 I20, Spain; ${ }^{2}$ Department of \\ Psychology, Universidad Autónoma de \\ Chile, Providencia, 7500000, Chile
}

Background: Academic engagement is a variable of vital importance in adolescence due to its relationship with academic adjustment and its protective role against risk behaviors. Therefore, the objective of this study was to find out the variables involved in its development.

Objective: The specific objectives were to analyze the relationship between emotional intelligence, self-esteem and academic engagement, and determine the mediating role of selfesteem in the relationship between emotional intelligence and engagement in adolescence.

Methods: The sample of 1287 high school students used for this filled in the Utrecht Work Engagement Scale Student, Brief Emotional Intelligence Inventory and the Rosenberg Self Esteem Scale.

Results: The results showed the existence of positive relationships between vigor, dedication and absorption with the emotional intelligence factors and self-esteem. Furthermore, the mediation models showed the direct effect of emotional intelligence on engagement of youths. Self-esteem acted as a mediator in the relationship between intrapersonal factors, stress management and adaptability of emotional intelligence and engagement.

Conclusion: Design of emotional intelligence intervention programs are recommended as a measure for promoting self-esteem and engagement in adolescence.

Keywords: emotional control, evaluation of oneself, adolescence, mediation models

\section{Introduction}

Interest in academic engagement has recently been growing. This is partly due to the involvement of this variable in reducing school dropouts and increasing student performance. Along with the connection of engagement with the academic adjustment indicators, it stands out because of its protective role against problematic adolescent behaviors, such as criminal acts and violence, substance use and depressive symptoms. ${ }^{1,2}$ Thus, as student engagement has been shown to be enabled through school intervention, its study is of special interest, especially in secondary education. ${ }^{3}$

\section{Importance of Academic Engagement}

Academic commitment, or engagement, refers to a psychological state characterized by the student's sense of belonging, attributing value to education, and participating in school, learning, studying and in curricular activities. ${ }^{4,5}$ Academic engagement is particularly characterized by vigor (referring to energy, willingness and persistence in making an effort to perform school activities), dedication (with regard to the sense of enthusiasm, inspiration, pride and importance attributed to it, that is, psychological identification with studies and academic activities) and
Correspondence: María del Mar Molero Jurado

Department of Psychology, Faculty of Psychology, University of Almería, Ctra Sacramento s/n, Almería, 04120, Spain Tel +34950015598

Emailmmj130@ual.es 
absorption (related to full concentration, without effort and intrinsic enjoyment, in academic demands, so that time seems to pass quickly and it is hard to detach oneself from activities). ${ }^{5}$

High levels of engagement in youths improve the competencies, skills and values necessary for academic success, at the same time they reduce participation in negative behaviors, enabling adolescents to make successful transition to adulthood. ${ }^{6,7}$ However, in spite of its importance, not all youths show high levels of academic engagement. ${ }^{8}$ Moreover, this variable tends to be unstable, changing over time, ${ }^{9}$ diminishing at the beginning of adolescence, ${ }^{10}$ especially in male students. ${ }^{11}$

Much of the research on academic engagement in adolescents has concentrated on the development and social relations of minors in the family, ${ }^{12-15}$ and in school, both with peers ${ }^{11,16-18}$ and teachers. ${ }^{19}$ However, beyond the social aspects, an important part of academic engagement is emotional in nature. ${ }^{10}$ Emotions are an active part of the academic engagement shown by youths, and behavioral manifestation of emotions appearing in the face of academic stressors may well be linked to academic engagement or to emotional disaffection. ${ }^{20}$

\section{Emotional Intelligence in Secondary Education}

Adolescence is a complex evolutionary moment in which youths must struggle with challenges and new individual, social and academic situations. ${ }^{21}$ Increased academic demands and expectations for successful promotion into the adult labor market, ${ }^{22}$ diminished motivation and structural changes ${ }^{23}$ usually appear at the beginning of high school. Maintaining adequate emotional control in different contextual and personal situations that take place during the school year are especially important in the student's adaptation to the school. ${ }^{24}$ Therefore, emotional intelligence is a necessary variable for adequate student performance during this stage, in which they not only need to have knowledge but also the socioemotional tools necessary to master them. ${ }^{25}$

Emotional intelligence in high school students is a predictor of adaptation, well-being and academic performance. ${ }^{26,27}$ It also protects against school burnout by increasing resilience and managing anxiety. ${ }^{28}$ Another variable linked to the school context which has been shown to be related is academic engagement. ${ }^{29,30}$ Adolescents who are conscientious and manage their emotions effectively adapt better to the setting and to schoolwork, and at the same feel a more emotional connection with the school. ${ }^{31}$ This has been shown in studies such as the one by Serrano and Andreu, ${ }^{29}$ where perception and regulation of emotional states acted as predictors of the dimensions of academic engagement. Studies done in other populations have found similar results. For example, Arias-Chávez, VeraBuitrón, Ramos-Quispe, and Pérez-Saavedra ${ }^{32}$ showed that the interpersonal, intrapersonal, adaptability and mood emotional intelligence factors were related to the vigor, dedication and absorption factors of engagement in university students, contrary to stress management which had very little relationship. However, studies such as the one by Zhen et $\mathrm{al}^{33}$ showed that stress management is important in coping with academic situations. Thus, youths who experience continuously high levels of stress from school demands may over time develop feelings of resignation, leading them to participate less or abandon their engagement in school activities. The interpersonal factor of emotional intelligence has also been confirmed in healthcare professionals along with stress management as a predictive variable of engagement and protection against burnout. ${ }^{34,35}$ In this respect, Fiorilli et al showed that emotional intensity acted as a predictor of emotional exhaustion factors and personal burnout in teachers. ${ }^{36}$ This is important, as burnout is considered erosion of the individual's engagement. ${ }^{37,38}$

Therefore, previous evidence seems to show that emotional intelligence and engagement are related variables. In addition, training in emotional competencies in the school has been shown to contribute to better engagement. ${ }^{25}$ Therefore, the hypothesis posed was that there would be positive relationships between student emotional intelligence dimensions and academic engagement $(\mathrm{H} 1)$.

\section{Self-Esteem in Adolescence and Its Relationship with Engagement and Emotional Intelligence}

Self-esteem is the main component of evaluation of oneself $^{39}$ and has an important role in individual development and adjustment. ${ }^{40,41}$ This variable is a complex trait, especially in adolescence, where specific domains, such as feelings of scholastic and athletic competence, social acceptance and physical appearance, along with overall self-esteem, tend to diminish upon reaching the middle stage (from14 to 16 years old). ${ }^{42}$ 
The influence of self-esteem in education has been related to behavior and connection with the school, as well as engagement levels. ${ }^{40,43,44}$ In this regard, Fredericks et $\mathrm{al}^{6}$ found that youths teased and excluded by the other students due to their cognitive or social ability, or how they look, showed less engagement. This could be due to the strong connection of overall selfesteem at this stage with the domains of physical appearance, social acceptance and close friendship, ${ }^{39}$ as well as the strong influence of evaluative standards on levels of self-esteem. ${ }^{45}$ Thus, adolescents may avoid academic activities and show less-positive attitudes toward the school when they do not feel highly regarded by their peers and feel their self-esteem threatened, seeking in turn, the company of other discontented students. ${ }^{6}$ On this basis, this study expected to find positive relationships between self-esteem and engagement, with youths with the highest self-esteem those who would also have higher scores on the components of academic engagement (H2).

In another vein, emotional intelligence has been shown to be involved in development and to have a close connection with self-esteem of youths. Specifically, adolescents who show high scores on all the components of emotional intelligence have more positive mood and can repair negative emotions in difficult situations, which enables them to develop an adjusted self-concept and selfesteem. Nevertheless, youths with an emotional intelligence profile marked by high levels of emotional repair and management and low in attention to them, likewise show high self-esteem and a favorable self-concept, contrary to those with low levels of emotional repair. This shows that emotion management contributes to adolescents having a more positive perception about themselves and their capabilities, as they are able to control their impulses and reactions better in adverse situations. ${ }^{46}$ In this vein, Romano et $\mathrm{al}^{47}$ mentioned that students with higher emotional intelligence managed the emotional burden related to school better by choosing the proper emotional strategies. At the same time, a study on the effect of an intervention program in emotional competencies showed improved self-esteem of adolescents and perceived control of events in their lives, such as those which take place in the school, by decreasing stress and improving emotional response, intrinsic motivation and perseverance. ${ }^{48}$ Thus, it seems that emotional competencies exert a positive effect on self-perception. And in turn, this promotes committed motivated action in situations that might come up. In line with this, academic self- esteem has been shown to be a mediator between emotional intelligence and academic results of youths. ${ }^{30}$ Therefore, the third hypothesis of this study was that selfesteem acts as a mediator between the emotional intelligence factors and academic engagement (H3).

\section{Objective}

According to Karababa, ${ }^{43}$ in order to understand the factors involved in academic engagement levels, it is of vital importance to increase knowledge of this variable of school experience, ${ }^{49}$ academic results and emotional wellbeing of youths, ${ }^{50}$ and to promote its improvement. Therefore, the objectives of this study were to analyze the relationships between the components of emotional intelligence, self-esteem and academic engagement in a sample of adolescents. And determine the mediating role of self-esteem in the emotional intelligenceacademic engagement relationship.

\section{Method \\ Participants}

A total of 1287 students, aged 14 to 18 , with a mean age of $15.11(S D=0.91)$ at public high schools in the province of Almeria (Spain) participated in this study. The distribution by sex was $47.1 \%(\mathrm{n}=606)$ boys and $52.9 \%(\mathrm{n}=681)$ girls, aged $15.12(S D=0.94)$ and $15.10(S D=0.88)$, respectively. $55.2 \%(\mathrm{n}=710)$ were in third grade and $44.8 \%(\mathrm{n}=577)$ were in fourth grade.

\section{Instruments}

Sociodemographic data (age, sex, grade, nationality, etc.) were collected with an ad hoc questionnaire.

Utrecht Work Engagement Scale Student (UWES-S). ${ }^{51}$ This scale is made up of 17 items for measuring adolescents' feelings of engagement in school. It contains six items that evaluate vigor, five items that measure dedication and six items that measure absorption in studies. With a seven-point Likert-type response scale (from never to always/every day). The vigor factor refers to the will to make an effort and persist in the face of difficulty (eg, When I get up in the morning, I feel like going to school or studying), dedication is related to feeling enthusiastic, proud and inspired by studies (eg, I am enthusiastic about my studies), and absorption refers to being happily immersed in study so that time passes quickly (eg, Time flies when I am doing my homework). The reliability is 
$\omega=0.82$ and $\mathrm{GLB}=0.85$ for vigor, $\omega=0.84$ and $\mathrm{GLB}=0.84$ for dedication, and $\omega=0.84$ and $\mathrm{GLB}=0.85$ in absorption.

Brief Emotional Intelligence Inventory (EQ-i-M20). ${ }^{52}$ This consists of 20 items which enable calculation of five factors: intrapersonal, interpersonal, stress management, adaptability and general mood. These factors refer to the capability for understanding one's own feelings (eg, It is easy for me to tell people how I feel) and emotions of others (eg, I understand how other people feel), the ability to stay in self-control in situations causing distress (eg, I get angry easily), flexibility in solving problems (eg, I can solve problems different ways) and feelings of happiness and optimism (eg, I am happy with the kind of person I am), respectively. The answer choices are rated on a four-point Likert-type scale (from that never happens to me to that always happens to me). The reliability in this study was: EQ-i-M20: $\omega=0.80, \mathrm{GLB}=0.89$; Intrapersonal: $\omega=0.82$, $\mathrm{GLB}=0.82$; Interpersonal: $\omega=0.62$, GLB $=0.68$; Stress management: $\omega=0.77$, GLB $=0.80$; Adaptability: $\omega=0.72$, $\mathrm{GLB}=0.73$; Mood: $\omega=0.87, \mathrm{GLB}=0.88$.

Self-esteem Scale. ${ }^{53}$ This scale estimates self-esteem in a unidimensional model developed for adolescents and adults, where feelings of respect and acceptance of oneself are evaluated. It consists of 10 items, with four answer choices which very from "very much agree" to "very much disagree". Several studies have analyzed the adequacy of its psychometric characteristics, with different populations. $^{54,55}$ In this study reliability was $\omega=0.86$ and $\mathrm{GLB}=0.90$.

\section{Procedure}

First, the school principals were contacted and a meeting was arranged to inform them about the objectives of the research and guarantee confidential treatment of data. When the pertinent permissions had been received, two members of the research team went to the schools to administer the questionnaires according to the session schedule. The tests were given in the usual classroom assigned to each group in the presence of their teacher/counselor. At the beginning of the session, before going on to filling in the questionnaires, the students were given the appropriate instructions and were offered time to ask any questions, and the anonymity of their answers was guaranteed, and therefore, that their privacy would be respected in statistical processing. The students filled out the tests anonymously and individually, in an estimated mean time of 25-30 minutes/session. In all cases, the ethical standards for research were complied with on an informed consent sheet by the parents or legal guardians of the participants, as well as the participants themselves. The study was approved by the University of Almeria Bioethics Committee (Ref: UALBIO2018/015) and complies with the guidelines outlined in the Declaration of Helsinki.

\section{Data Analysis}

First, to identify the relationships of the emotional intelligence factors with self-esteem and academic engagement, the Pearson's correlation coefficient was calculated. Then, a comparison of means was performed to determine any significant differences in engagement between the self-esteem groups (low, medium, high). A Welch's $F$-test was applied for this, ${ }^{56}$ using $\widehat{\omega}_{p}^{2}$ to estimate the effect size. ${ }^{57}$ The Welch's $F$-test is recommended for unequal sample sizes and when the assumption of homogeneity of variances for one-way ANOVA is not met) in this case, Levene's test showed $\mathrm{p}<0.05$ significance in two out of three dependent variables).

The SPSS version $24.0^{58}$ statistical package for Windows (IBM Corp. Released 2016) was used for data processing and analysis, and the ggplot $2^{59}$ and ggstatsplot $^{60}$ packages with jamovi v.1.2 $2^{61}$ statistical software were used for analysis and graphics. Finally, mediation models were computed for analysis of the direct effects of each of the emotional intelligence dimensions on the components of academic engagement, and also to identify the behavior of self-esteem as a mediator in the emotional intelligence-engagement relationship (indirect effects).

\section{Results}

\section{Adolescent Academic Engagement, Emotional Intelligence and Self-Esteem}

Table 1 shows the results of the correlation analysis, where significant relationships were observed between the three engagement dimensions and the emotional intelligence factors and self-esteem, all of them positive.

Figure $1 \mathrm{~A}-\mathrm{C}$ shows the results of the comparison of means in each of the academic engagement dimensions between self-esteem groups (low, medium, high). In all cases, statistically significant differences were found between the self-esteem groups, as revealed by the Welch's unequal variances $t$-test. Furthermore, the Bayes Factor (BF01) provided negative evidence in favor of the null hypothesis for all three engagement components. 
Table I Pearson's Correlations: Academic Engagement, Emotional Intelligence and Self-Esteem

\begin{tabular}{|l|l|c|c|c|c|c|c|}
\hline \multicolumn{2}{|l|}{} & INTRA & INTER & STR_M & ADAPT & MOOD & SE \\
\hline Vigor & Pearson's r & 0.201 & 0.157 & 0.126 & 0.201 & 0.202 & 0.172 \\
& P-value & $<0.001$ & $<0.001$ & $<0.001$ & $<0.001$ & $<0.001$ & $<0.00$ I I \\
& Upper 95\% Cl & 0.253 & 0.210 & 0.180 & 0.253 & 0.254 & 0.226 \\
& Lower 95\% Cl & 0.148 & 0.103 & 0.072 & 0.148 & 0.149 & 0.117 \\
\hline \multirow{2}{*}{ Dedication } & Pearson's r & 0.198 & 0.193 & 0.112 & 0.207 & 0.223 & 0.192 \\
& P-value & $<0.001$ & $<0.001$ & $<0.001$ & $<0.001$ & $<0.001$ & $<0.001$ \\
& Upper 95\% Cl & 0.250 & 0.245 & 0.165 & 0.259 & 0.274 & 0.245 \\
& Lower 95\% Cl & 0.145 & 0.140 & 0.057 & 0.155 & 0.171 & 0.138 \\
\hline \multirow{2}{*}{ Absorption } & Pearson's r & 0.191 & 0.148 & 0.084 & 0.177 & 0.186 & 0.151 \\
& P-value & $<0.001$ & $<0.001$ & 0.003 & $<0.001$ & $<0.001$ & $<0.001$ \\
& Upper 95\% Cl & 0.243 & 0.201 & 0.138 & 0.230 & 0.238 & 0.205 \\
& Lower 95\% Cl & 0.138 & 0.094 & 0.029 & 0.124 & 0.133 & 0.096 \\
\hline
\end{tabular}

Abbreviations: INTRA, intrapersonal; INTER, interpersonal; STR_M, stress management; ADAPT, adaptability; MOOD, mood; SE, self-esteem.

The Mediating Role of Self-Esteem in the Relationship Between Emotional

\section{Intelligence and Academic Engagement}

Based on these results, we decided to find out whether self-esteem could be mediating in the relationship established between emotional intelligence and academic engagement in adolescents. Several different simple mediation models were computed for this, taking the components of emotional intelligence as the independent variable in each case: Intrapersonal $\left(\mathrm{X}_{1}\right)$, interpersonal $\left(\mathrm{X}_{2}\right)$, stress management $\left(\mathrm{X}_{3}\right)$, adaptability $\left(\mathrm{X}_{4}\right)$, and $\operatorname{mood}\left(\mathrm{X}_{5}\right)$. In all the models, self-esteem was the mediator (M). Finally, the academic engagement dimensions (vigor, dedication and absorption, respectively) were entered as the dependent variable (Y) in each of the models.
A

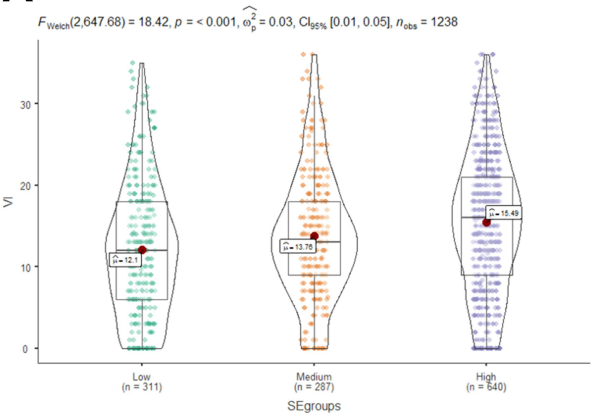

C

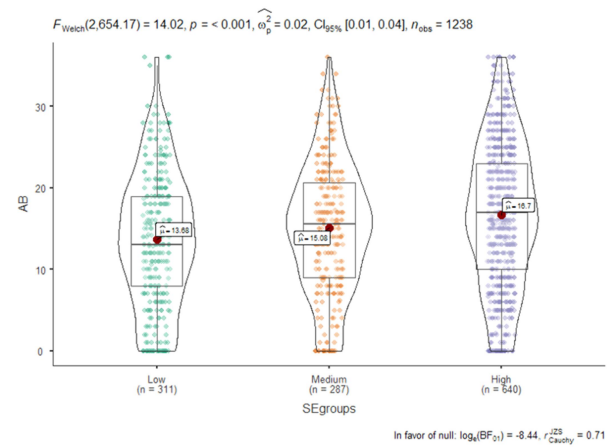

B

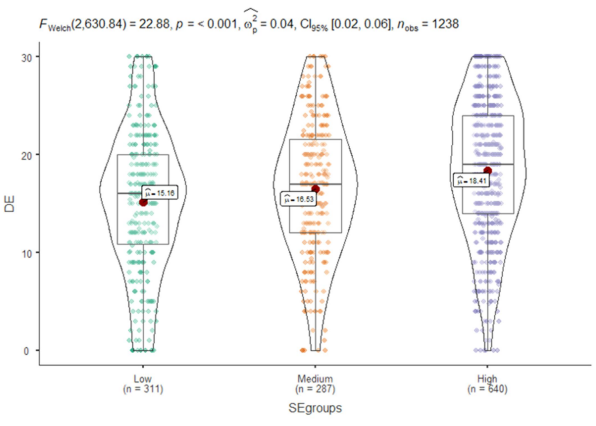

Figure I Violin plots comparing academic engagement between self-esteem groups. Note: (A) vigor; (B) dedication; (C) absorption. Abbreviations: $\mathrm{VI}$, vigor; $\mathrm{DE}$, dedication; $\mathrm{AB}$, absorption. 
In Model 1 , estimation of the direct effects $(X \rightarrow Y)$ revealed significant relationships of all the factors of emotional intelligence on the vigor dimension of academic engagement (Figure 2). The significant indirect effects $\left(a_{x} b\right)$ were found in the intrapersonal factor $\mathrm{B}=0.09, \mathrm{SE}=0.02,95 \% \mathrm{CI}(0.047$, $0.141), \mathrm{Z}=3.98, \mathrm{p}<0.001,16.9 \%{ }_{\mathrm{Md}}$; stress management $\mathrm{B}=0.08, \mathrm{SE}=0.02,95 \% \mathrm{CI}(0.046,0.126), \mathrm{Z}=4.27, \mathrm{p}<$ $0.001,23.1 \%_{\mathrm{Md}}$; and adaptability $\mathrm{B}=0.11, \mathrm{SE}=0.02,95 \% \mathrm{CI}$ (0.056, 0.165), $\mathrm{Z}=4.01, \mathrm{p}<0.001,15.6 \%_{\mathrm{Md}}$. However, neither self-esteem $\mathrm{B}=0.03, \mathrm{SE}=0.01,95 \% \mathrm{CI}(-0.005$, $0.067), Z=1.67, p=0.094$, nor $\operatorname{mood} B=0.09, S E=0.07$, $95 \% \mathrm{CI}(-0.063,0.244), \mathrm{Z}=1.15, \mathrm{p}=0.249$ mediated in the relationship of the interpersonal factors with vigor.

Model 2, as shown in Figure 3, found significant direct effects of all the emotional intelligence factors on the academic engagement dedication factor. Indirect effects were significant in the intrapersonal factor $\mathrm{B}=0.09, \quad \mathrm{SE}=0.02,95 \%$ CI $(0.054,0.136)$, $\mathrm{Z}=4.55, \mathrm{p}<0.001,19.5 \% \mathrm{Md} ;$ stress management $\mathrm{B}=0.08, \mathrm{SE}=0.01,95 \%$ CI $(0.050,0.123)$, $\mathrm{Z}=4.66, \mathrm{p}<0.001,29.3 \%_{\mathrm{Md}} ;$ and adaptability $\mathrm{B}=0.11, \mathrm{SE}=0.02,95 \% \mathrm{CI}(0.063,0.160), \mathrm{Z}=$
4.54, $\mathrm{p}<0.001,18 \% \mathrm{Md}$. However, self-esteem was not a mediator in the relationship of the interpersonal factors $\mathrm{B}=0.03, \mathrm{SE}=0.01,95 \% \mathrm{CI}(-0.004,0.064)$, $\mathrm{Z}=1.69, \mathrm{p}=0.092$ or $\operatorname{mood} \mathrm{B}=0.09, \mathrm{SE}=0.06,95 \%$ CI $(-0.035,0.230), Z=1.44, p=0.150$ with dedication.

Finally, in Model 3, direct effects with statistical significance were found of all the emotional intelligence dimensions on academic engagement's absorption (Figure 4). The indirect effects in this model were significant by the paths originating in the intrapersonal factor $\mathrm{B}=0.08$, $\mathrm{SE}=0.02,95 \%$ CI $(0.034,0.128), \mathrm{Z}=3.42, \mathrm{p}<0.001$, $15 \%{ }_{\mathrm{Md}}$; stress management $\mathrm{B}=0.08, \mathrm{SE}=0.02,95 \% \mathrm{CI}$ (0.041, 0.121), $\mathrm{Z}=4.01, \mathrm{p}<0.001,30.9 \%_{\mathrm{Md}}$; and adaptability $\mathrm{B}=0.10, \mathrm{SE}=0.02,95 \% \mathrm{CI}(0.045,0.155), \mathrm{Z}=$ $3.59, \mathrm{p}<0.001,15.8 \%_{\mathrm{Md}}$. Moreover, the results did not support the mediation function of self-esteem when the interpersonal factor $\mathrm{B}=0.02, \mathrm{SE}=0.01,95 \% \mathrm{CI}(-0.005$, $0.061), Z=1.65, p=0.098$ or $\operatorname{mood} B=0.06, S E=0.08$, $95 \% \mathrm{CI}(-0.090,0.227), \mathrm{Z}=0.84, \mathrm{p}=0.397$ were taken as predictors of absorption.

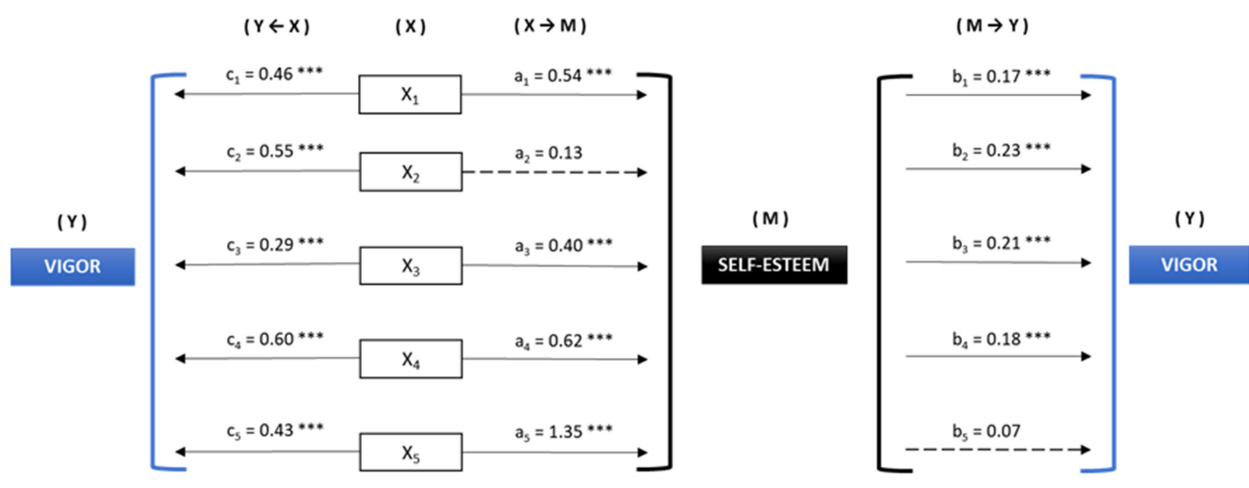

Figure 2 Mediation model I (vigor). Path estimates.

Notes: $X_{1}=$ intrapersonal; $X_{2}=$ interpersonal; $X_{3}=$ stress management; $X_{4}=$ adaptability; $X_{5}=$ mood. $* * * p<0.001$.

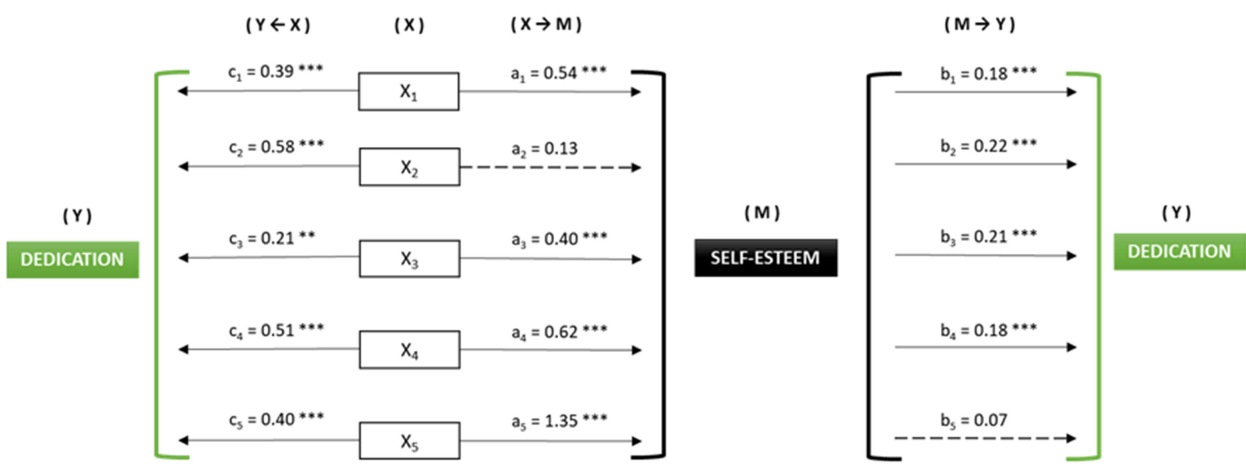

Figure 3 Mediation model 2 (dedication). Path estimates.

Notes: $X_{1}=$ intrapersonal; $X_{2}=$ interpersonal; $X_{3}=$ stress management; $X_{4}=$ adaptability; $X_{5}=$ mood. ${ }^{* *} p<0.01$, **** $<0.001$. 


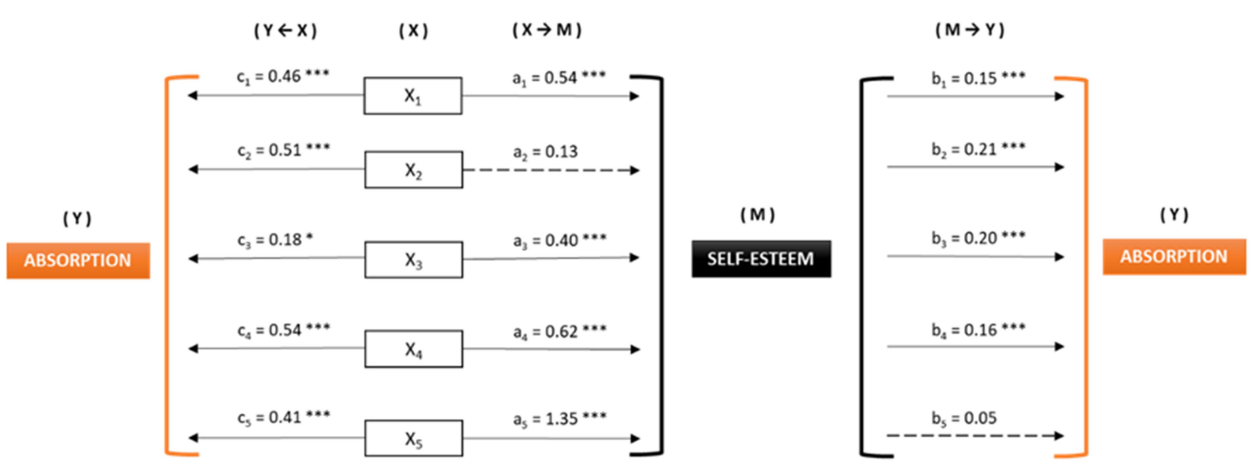

Figure 4 Mediation model 3 (absorption). Path estimates.

Notes: $X_{1}=$ intrapersonal; $X_{2}=$ interpersonal; $X_{3}=$ stress management; $X_{4}=$ adaptability; $X_{5}=$ mood. ${ }^{*} p<0.05, * * * p 0.001$.

\section{Discussion}

The involvement of engagement in academic adjustment and emotional well-being ${ }^{1,50}$ as well as reduction in risk behaviors $^{2}$ has led to a growing interest in the variables involved in their development and promotion in the secondary stage. ${ }^{3}$ As emotions are an active part of academic engagement, ${ }^{10,20}$ the objective of this study was to delve into emotional intelligence and self-esteem as related emotional variables. The results confirmed the first hypothesis of the study, as positive relationships were found between the dimensions of emotional intelligence and academic engagement of high school students. ${ }^{29,30}$ The second hypothesis was equally confirmed on finding positive correlations between vigor, dedication and absorption of engagement with self-esteem. These results coincide with those in the literature. ${ }^{34,40,43,44}$ In like manner, when comparing the scores in the engagement dimensions between youths with low, medium and high self-esteem, significant differences were found where students with high levels of self-esteem had the highest scores in the three academic engagement dimensions. Thus, adolescents who show the most positive evaluation about themselves are those who are the most committed and participate most actively in school academic activities. On the contrary, those with the lowest levels of overall self-esteem cope with academic activities without energy, enthusiasm or enjoyment, and could develop emotional disaffection from studies. ${ }^{20}$ This may be due to the heavy weight of the evaluative aspect of self-esteem during this stage, ${ }^{45}$ where the school is practically the center of their lives. Thus, feeling inferior or looked down on by the others can lead adolescents to distance themselves from academic activities and show an attitude toward the school that is not very positive. ${ }^{6}$
Moreover, the effect of emotional intelligence on each component of academic engagement, as well as the ability of self-esteem to mediate in this relationship, was confirmed. The results partially confirmed the hypothesis that there would be direct effects of all the components of emotional intelligence on the engagement factors, with self-esteem as the mediator. Thus, even though there were direct effects of all the factors of emotional intelligence on vigor, dedication and absorption, the mediation model revealed the indirect predictive role only for the intrapersonal, stress management and adaptability factors of emotional intelligence through self-esteem. This could be due to the emotional intelligence interpersonal factor and mood state, although they are directly important in academic commitment, they do not exert a determining influence on self-esteem levels of the youths and could have repercussions, in turn, on engagement. Emotional skills therefore promoted positive attitudes toward study and educational tasks. ${ }^{31}$ In turn, students who perceive, regulate and adjust their emotional states satisfactorily feel optimistic and can palliate negative emotions that arise about themselves. ${ }^{46}$ This promotes positive evaluation and feelings of well-being toward their self-concept. It also generates greater responsibility and motivation of adolescents toward the academic environment, ${ }^{48}$ who cope with vitality and enthusiasm, persevering in spite of problems which could come up in doing homework or study.

All of the above shows the importance of self-esteem in this stage, when its trajectory becomes even more complicated. Thus, intervention in emotional competences in high school is suggested as an effective measure for assisting youths in their struggle with the challenges they face in adolescence. And promoting self-esteem and 
a positive academic trajectory, given the involvement of engagement in performance and continuing with studies. ${ }^{1-3,31}$

This study had some limitations. In the first place, we should point out that there are few studies analyzing the variables presented together, which impedes construction of a theoretical model sustaining our findings. In future, it would be recommendable to continue inquiring into the relationship of emotional intelligence, academic engagement and self-esteem during adolescence to find out, for example, the stability of these findings in the different stages of puberty, in other social realities or by gender. With regard to the last variable, given its involvement in the construction of self-esteem and the differences it marks in emotional intelligence, its inclusion in future studies would be of special interest. Furthermore, it should be borne in mind that the constructs analyzed were evaluated with self-reports, and therefore conditioned by individual subjectivity. Finally, the different models proposed in the literature for constructs included in this study must be added to the scarcity of studies mentioned, which can interfere with comparison of the results.

\section{Conclusion}

Adolescent engagement in study is a psychological state of vital importance, because of its involvement in other behaviors that promote better adjustment and long-term individual trajectory. This study showed the involvement of emotional intelligence in increasing levels of engagement of youths, where self-esteem acts as a mediator in this relationship with the intrapersonal, stress management and adaptability factors. Therefore, promotion of emotional competences in secondary education can be an effective measure for increasing the enthusiasm, energy and interest of adolescents in academic activities. And, in turn, generate higher levels of self-esteem, which usually diminishes in this stage, promoting feelings of competence for coping with challenges, such as those which arise in the academic environment.

\section{Acknowledgments}

The present study was undertaken in collaboration with the Peer violence and alcohol and tobacco use in Secondary Education program: an augmented reality program for detection and intervention (Reference: EDU2017-88139R), funded by the State Research Program, Development and Innovation Oriented to the Challenges of Society, within the framework of the State Plan for Scientific and
Technical Research and Innovation, and co-financing with Structural Funds of the European Union.

\section{Disclosure}

The authors would like to declare that we have no conflicts of interest for this work.

\section{References}

1. Wang MT, Fredricks JA. The reciprocal links between school engagement, youth problem behaviors, and school dropout during adolescence. Child Dev. 2014;85:722-737. doi:10.1111/cdev.12138

2. Yang C, Sharkey JD, Reed LA, Chen C, Dowdy E. Bullying victimization and student engagement in elementary, middle, and high schools: moderating role of school climate. Sch Psychol $Q$. 2018;33:54-64. doi:10.1037/spq0000250

3. Fredericks JA, Filsecker M, Lawson MA. Student engagement, context, and adjustment: addressing definitional, measurement, and methodological issues. Learn Instr. 2016;43:1-4. doi:10.1016/j. learninstruc.2016.02.002

4. Glanville JL, Wildhagen T. The measurement of school engagement: assessing dimensionality and measurement invariance across race and ethnicity. Educ Psychol Meas. 2007;67:1019-1041. doi:10.1177/ 0013164406299126

5. Schaufeli W, Salanova M, González-Romá V, Bakker AB. The measurement of engagement and burnout: a two sample confirmatory factor analytic approach. $J$ Happiness Stud. 2002;3:71-92. doi:10.1023/A:1015630930326

6. Fredericks JA, Parr AK, Amemiya JL, Wang MT, Bauer S. What matters for urban adolescents' engagement and disengagement in school: a Mixed-Methods Study. J Adolesc Res. 2019;34:491-527. doi: $10.1177 / 0743558419830638$

7. Martos Á, Pérez-Fuentes MC, Molero MM, Gázquez JJ, Simón MM, Barragán AB. Burnout y engagement en estudiantes de Ciencias de la Salud [Burnout and engagement in Health Sciences students]. Eur J Investig Health Psychol Educ. 2018;8:23-36. doi:10.30552/ejihpe. v8i1.223

8. Salmela-Aro K, Moeller J, Schneider B, Spicer J, Lavonen J. Integrating the light and dark sides of student engagement using person-oriented and situation-specific approaches. Learn Instr. 2016;43:61-70. doi:10.1016/j.learninstruc.2016.01.001

9. Wang MT, Chow A, Hofkens T, Salmela-Aro K. The trajectories of student emotional engagement and school burnout with academic and psychological development: findings from Finnish adolescents. Learn Instr. 2015;36:57-65. doi:10.1016/j.learninstruc.2014.11.004

10. Wilcox G, McQuay J, Blackstaffe A, Perry R, Hawe P. Supporting academic engagement in boys and girls. Can J Sch Psychol. 2017;33:179-192. doi:10.1177/0829573517703239

11. Engels MC, Colpin H, Wouters S, et al. Adolescents' peer status profiles and differences in school engagement and loneliness trajectories: a person-centered approach. Learn Individ Differ. 2019;75:101759. doi:10.1016/j.lindif.2019.101759

12. Simons LG, Steele ME. The negative impact of economic hardship on adolescent academic engagement: an examination parental investment and family stress processes. $J$ Youth Adolesc. 2020;49:973-990. doi:10.1007/s10964-020-01210-4

13. Rodríguez A, Revuelta L, Sarasa M, Fernández O. The role of parental socialization styles in school engagement and academic performance. Eur J Educ Psychol. 2018;11:123-139. doi:10.30552/ ejep.v11i2.226

14. Rodríguez-Fernández A, Antonio-Aguirre I, Ramos-Díaz E, Revuelta-Revuelta $\mathrm{L}$. The role of affect-communication and rule setting in perceived family support and school adjustment. Eur J Educ Psychol. 2020;13:5-18. doi:10.30552/ejep.v13i1.288 
15. Trost K, Eichas K, Ferrer-Wreder L, Galanti MR. The study of family context: examining its role for identity coherence and adolescent adjustment for Swedish adolescents. $J$ Early Adolesc. 2020;40:165-196. doi:10.1177/0272431619833479

16. Rogers AA, Delay D, Martin CL. Traditional masculinity during the middle school transition: associations with depressive symptoms and academic engagement. $J$ Youth Adolesc. 2017;46:709-724. doi:10.1007/s10964-016-0545-8

17. Zhang X, Pomerantz EM, Qin L, Logis H, Ryan AM, Wang M. Characteristics of likability, perceived popularity, and admiration in the early adolescent peer system in the United States and China. Dev Psychol. 2018;54:1568-1581. doi:10.1037/dev0000544

18. Zhang X, Pomerantz EM, Qin L, Logis H, Ryan AM, Wang M. Early adolescent social status and academic engagement: selection and influence processes in the United States and China. J Educ Psychol. 2019;111:1300-1316. doi:10.1037/edu0000333

19. Strati AD, Schmidt JA, Maier KS. Perceived challenge, teacher support, and teacher obstruction as predictors of student engagement. J Educ Psychol. 2017;109:131-147. doi:10.1037/edu0 000108

20. Skinner EA, Pitzer JR, Steele JS. Can student engagement serve as a motivational resource for academic coping, persistence, and learning during late elementary and early middle school? Dev Psychol. 2016;52:2099-2117. doi:10.1037/dev0000232

21. Ortuño-Sierra J, Fonsexa-Pedrero E, Sastre I Riba S, Muñiz J. Patterns of behavioural and emotional difficulties through adolescence: the influence of prosocial skills. An De Psicol. 2017;33:48-56. doi:10.6018/analesps.32.3.225031

22. Högberg B, Strandh M, Hagquist C. Gender and secular trends in adolescent mental health over 24 years - the role of school-related stress. Soc Sci Med. 2020;250:112890. doi:10.1016/j.socscimed.20 20.112890

23. Tu KM, Cai T, Li X. Adolescent coping with academic challenges: the role of parental socialization of coping. $J$ Adolesc. 2020;81:27-38. doi:10.1016/j.adolescence.2020.03.008

24. Usán P, Salavera C, Mejías JJ. Relaciones entre la inteligencia emocional, el burnout académico y el rendimiento en adolescentes escolares [Relationships between emotional intelligence, academic burnout and performance in school adolescents]. CES PSICOL. 2020;13:125-139. doi:10.21615/cesp.13.1.8

25. Pozo-Rico T, Sánchez B, Castejón JL, Gilar R. Training course on emotional intelligence: the experience of emotional intelligence in a secondary education project. Publicaciones. 2018;48:235-255. doi: $10.30827 /$ publicaciones.v48i2.8342

26. Costa A, Faria L. Implicit theories of emotional intelligence, ability and trait-emotional intelligence and academic achievement. Psychol Topics. 2020;29:43-61. doi:10.31820/pt.29.1.3

27. Sánchez-García MA, Lucas-Molina B, Fonseca-Pedrero E, PérezAlbéniz A, Paino M. Emotional and behavioral difficulties in adolescence: relationship with emotional well-being, affect, and academic performance. An De Psicol. 2018;54:482-490. doi:10.6018/ analesps.34.3.296631

28. Fiorrilli C, Farina E, Buonomo I, et al. Trait emotional intelligence and school burnout: the mediating role of resilience and academic anxiety in high school. Int $J$ Environ Res Public Health. 2020;17:3058. doi:10.3390/ijerph17093058

29. Serrano C, Andreu Y. Perceived emotional intelligence, subjective well-being, perceived stress, engagement and academic achievement of adolescents. Rev De Psicodidáctica. 2016;21:357-374. doi:10.1387/RevPsicodidact.14887

30. Usán P, Salavera C, Mejías JJ, Marino A, Jarie L. Relaciones de la inteligencia emocional, burnout y compromiso académico con el rendimiento escolar de estudiantes adolescents [Relationships of emotional intelligence, burnout and academic commitment with the school performance of adolescent students]. Arch Med. 2019;19:197-207. doi:10.30554/archmed.19.2.3256.2019
31. Sandovici A. The relationship between emotional intelligence and academic achievement in adolescents. Rom $J$ Sch Psychol. 2017;10:35-50.

32. Arias-Chávez D, Vera-Buitrón MP, Ramos-Quispe T, Pérez-Saavedra S. Engagement e Inteligencia emocional en estudiantes de una universidad privada en la ciudad de Arequipa [Engagement and emotional intelligence in students of a private university in the city of Arequipa]. Propósi Represent. 2020;8:e423. doi:10.20511/pyr2020.v8n1.423

33. Zhen R, Wu X, Zhou X. Longitudinal development of adolescent academic engagement following the Wenchuan earthquake: domain-specific trajectories. Sch Psychol Int. 2019;41:89-109. doi: $10.1177 / 0143034319884615$

34. Pérez-Fuentes MC, Molero MM, Gázquez JJ, Oropesa NF. The role of emotional intelligence in engagement in nurses. Int $J$ Environ Res Public Health. 2018;15:1915. doi:10.3390/ijerph15091915

35. Pérez-Fuentes MC, Molero MM, Gázquez JJ, Simón MM. Analysis of burnout predictors in nursing: risk and protective psychological factors. Eur J Psychol Appl Leg Context. 2018;11:33-40. doi:10.5093/ejpalc2018a13

36. Fiorilli C, Gabola P, Pepe A, et al. The effect of teachers' emotional intensity and social support on burnout syndrome. A comparison between Italy and Switzerland. Eur Rev Appl Psychol. 2015;65:275-283. doi:10.1016/j.erap.2015.10.003

37. Schaufeli WB, Leiter MP, Maslach C. Burnout: 35 years of research and practice. Career Dev Int. 2009;14:204-220. doi:10.1108/ 13620430910966406

38. Fiorilli C, De Stasio S, Benevene P, et al. Copenhagen Burnout Inventory (CBI): a validation study in an italian teacher group. TPM Test Psychom Methodol Appl Psychol. 2015;22:537-551.

39. von Soest T, Wichstøm L, Kvalem IL. The development of global and domain-specific self-esteem from age 13 to 31. J Pers Soc Psychol. 2016;110:592-608. doi:10.1037/pspp0000060

40. Preeti KR, Behmani R, Singh K. Impact of self-esteem and adjustment on academic performance of adolescents. IJHW. 2016;7:133-135.

41. Soto-Sanz V, Piqueras JA, Rodríguez-Martín J, et al. Self-esteem and suicidal behavior in youth: a meta-analysis of longitudinal studies. Psicothema. 2019;31:246-254. doi:10.7334/psicothema2018.339

42. Białecka-Pikul M, Stępień-Nycz M, Sikorska I, Topolewska-Siedzik E, Cieciuch J. Change and consistency of self-esteem in early and middle adolescence in the context of school transition. $J$ Youth Adolesc. 2019;48:1605-1618. doi:10.1007/s10964-019-01041-y

43. Karababa A. The reciprocal relationships between school engagement and self-esteem among Turkish early adolescents: a three-wave cross-lagged model. Child Youth Serv Rev. 2020;116:105114. doi:10.1016/j.childyouth.2020.105114

44. Virtanen TE, Kiuru N, Lerkkanen MK, Poikkeus AM, Kuorelahti M. Assessment of student engagement among junior high school students and associations with self-esteem, burnout, and academic achievement. $J$ Educ. 2016;8:136-157.

45. Kang Y. The relationship between contingent self-esteem and trait self-esteem. Soc Behav Pers. 2019;47:1-19. doi:10.2224/sbp.7575

46. Martínez-Monteagudo MC, Inglés CJ, Suriá R, Lagos N, Delgado B, García-Fernández JM. Emotional intelligence profiles and self-concept in Chilean adolescents. Curr Psychol. 2019;1-8. doi:10.1007/s12144-019-00350-6

47. Romano L, Tang X, Hietajärvi L, et al. Students' trait emotional intelligence and perceived teacher emotional support in preventing burnout: the moderating role of academic anxiety. Int J Environ Res Public Health. 2020;17:4771. doi:10.3390/ijerph17134771

48. Lakes K, Nguyen HM, Jones M, Schuck SEB, Am I. Me: adolescent perspectives of a school-based universal intervention program designed to promote emotional competence. Int $J$ Emot Educ. 2019;11:97-114.

49. Wang MT, Holcombe R. Adolescents' perceptions of school environment, engagement, and academic achievement in middle school. Am Educ Res J. 2010;47:633-662. doi:10.3102/0002831209361209 
50. Moreira P, Cunha D, Inman RA. An integration of multiple student engagement dimensions into a single measure and validity-based studies. J Psychoeduc Assess. 2019;38:564-580. doi:10.1177/ 0734282919870973

51. Schaufeli WB, Bakker AB UWES Utrecht work engagement scale preliminary manual. Occupational Health Psychology Unit; 2003.

52. Pérez-Fuentes MC, Gázquez JJ, Mercader I, Molero MM. Brief emotional intelligence inventory for senior citizens (EQ-I-M20). Psicothema. 2014;26:524-530. doi:10.7334/psicothema2014.166

53. Rosenberg M. Society and the Adolescent Self-Image. Princeton, NJ: Princeton University Press; 1965.

54. Gnambs T, Scharl A, Schroeders U. The structure of the Rosenberg Self-Esteem Scale. Z Psychol. 2018;226:14-29. doi:10.1027/21512604/a000317

55. Schmitt DP, Allik J. Simultaneous administration of the Rosenberg Self-Esteem Scale in 53 Nations: exploring the universal and culture-specific features of global self-esteem. J Pers Soc Psychol. 2005;89:623-642. doi:10.1037/0022-3514.89.4.623
56. Delacre M, Leys C, Mora YL, et al. Taking parametric assumptions seriously: arguments for the use of Welch's F-test instead of the Classical F-test in One-Way ANOVA. Int Rev Soc Psychol. 2019;32:13. doi:10.5334/irsp.198

57. Tabachnick BG, Fidell LS. Using Multivariate Statistics. 5th ed. MA, United States: Allyn \& Bacon/Pearson Education; 2007.

58. IBM Corp. Released 2016. IBM SPSS Statistics for Windows, Version 24.0. Armonk, NY: IBM Corp; 2016.

59. Wickham H, Chang W, Henry L, et al. ggplot2: create elegant data visualisations using the grammar of graphics. [R package]; 2018. Available from https://CRAN.R-project.org/package=ggplot2. Accessed March 5, 2021.

60. Patil I ggstatsplot: 'ggplot2' based plots with statistical details. [R package]; 2018. Available from https://CRAN.R-project.org/pack age $=$ ggstatsplot. Accessed March 5, 2021.

61. The jamovi project. Jamovi, Version 1.2 [Computer Software]. Sydney: Australia; 2020.
Psychology Research and Behavior Management

\section{Publish your work in this journal}

Psychology Research and Behavior Management is an international, peer-reviewed, open access journal focusing on the science of psychology and its application in behavior management to develop improved outcomes in the clinical, educational, sports and business arenas. Specific topics covered in the journal include: Neuroscience, memory and decision making; Behavior modification and management; Clinical
Dovepress

applications; Business and sports performance management; Social and developmental studies; Animal studies. The manuscript management system is completely online and includes a very quick and fair peer-review system, which is all easy to use. Visit http://www. dovepress.com/testimonials.php to read real quotes from published authors. 